\title{
STUDIES OF THE TREATMENT AND PATHOPHYSIOLOGY OF ACUTE SPINAL CORD INJURY IN PRIMATES
}

\author{
By C. H. Tator, M.D., Ph.D., F.R.C.S.(C) and LüDer DeECKe, M.D. ${ }^{1}$ \\ Department of Surgery, Division of Neurosurgery, \\ University of Toronto, Canada
}

RECENTLY, new methods have been developed for treating the injured spinal cord and for studying conduction in the injured cord. For example, it has been shown in experimental animals with cord injury, that local hypothermic perfusion of the traumatised cord is therapeutically effective, and that detection of cortical evoked responses may be of prognostic value. The present report examines the value of local hypothermic and normothermic perfusion in spinal cord compression injuries in monkeys. In addition, the value and feasibility of spinal neurophysiological recording and stimulation during operation were examined.

An inflatable silastic cuff was passed extradurally around the spinal cord of monkeys at $\mathrm{T} 9$ and a circumferential compression injury made by inflating the cuff to a given pressure for a given duration. The afferent volley following stimulation of the exposed sciatic nerve was recorded on the dorsum of the cord by means of extradural silver ball electrodes connected to a pre-amplifier and a storage oscilloscope. The potentials were studied before, immediately after and up to three hours after injury. Furthermore, bipolar stimulation of descending spinal pathways, presumably the pyramidal tract (PT), and observations of hind limb motor responses were carried out. At three hours, the dura was opened in those animals to be perfused, and perfusion was carried out locally for three hours with normotonic solutions at either $5^{\circ} \mathrm{C}$ or $36^{\circ} \mathrm{C}$. In those animals not receiving perfusion, the dura was not opened, and these animals served as controls. All animals were observed for I2 weeks post-injury with neurological recovery graded 0 to 4 in each animal, grade 0 denoting no recovery and grade 4 full recovery of motor function. Evaluation was done without information about the treatment given.

Twenty monkeys received a compression injury with the cuff inflated to 350 $\mathrm{mm}$. Hg for five minutes. In IO, the dura was opened at three hours, the cords were perfused at $5^{\circ} \mathrm{C}$. for three hours, and at $\mathrm{I} 2$ weeks the grades of recovery in the Io totalled 24. In the other Io monkeys the dura was not opened, no perfusion was performed and the recovery grades totalled II. The difference is significant for both recovery $v s$ no recovery $\left(\mathrm{X}^{2}=3.8 \mathrm{I} ; 0.05>\mathrm{Po} .025\right)$ and for the totals of the grades (Wilcoxon two sample test: $0.05>\mathrm{P}>0.025$ ). Twenty additional monkeys were injured at $400 \mathrm{~mm}$. $\mathrm{Hg}$ for five minutes. In IO, the dura was opened, the cords perfused at $5^{\circ} \mathrm{C}$. for three hours and the recovery grades totalled $\mathrm{I} 7$. The remaining Io were treated the same except that perfusion was performed at $36^{\circ} \mathrm{C}$. and the recovery grades totalled 25 . This difference is not significant $(P>0 \cdot I)$. However, the $36^{\circ} \mathrm{C}$. perfusion group was significantly better than the dura-closed, non-perfused group, although the cuff pressure had increased by $50 \mathrm{~mm}$. Hg $\left(\mathrm{X}^{2}\right.$ and Wilcoxon, both $\left.0.05>\mathrm{P}>0.025\right)$.

1 On scholarly leave from the Department of Neurology, Universityof Ulm, Germany. 
The afferent volley was recorded from the dorsum of the spinal cord inferior to the injury site both before and after the injury. It was abolished above the site of injury in seven out of eight monkeys injured at $350 \mathrm{~mm} . \mathrm{Hg}$ and in all of I4 monkeys injured at $400 \mathrm{~mm}$. Hg. At the injury site the potential showed a characteristic shape, consisting of a deep positive sink due to killed end recording. The PT stimulation was somewhat less reliable. The motor response was abolished in only three out of five monkeys injured at $350 \mathrm{~mm}$. $\mathrm{Hg}$ and in seven out of thirteen monkeys injured at $400 \mathrm{~mm}$. $\mathrm{Hg}$. In the others it was still obtainable at higher thresholds. The persistence was most likely due to current loops bypassing the injury site and exciting the stumps of distal PT axons, because a motor response was not obtained when stimulation was carried out from a more remote laminectomy site at $\mathrm{T}_{3}$.

The results show that the combination of durotomy and normothermic perfusion yielded better neurological recovery than durotomy plus hypothermic perfusion. This is the first report of the use of normothermic perfusion for spinal cord injury, and indicates that the benefits ascribed to hypothermia in previous studies may actually have been due to the perfusion alone. The recording and stimulation experiments with extradural electrodes were easily accomplished and valuable for determining the completeness and reproducibility of the spinal cord compression injuries. Without averaging techniques they provide the same and additional information as cortical evoked responses. Both spinal stimulation and recording may also be of value clinically for assessing the severity of an injury and the response to treatment. 